\title{
Study and Development of Barnyard Millet Based Ready to Eat Product
}

\author{
G. Sudha Devi* and V. Palanimuthu \\ ${ }^{1}$ PFE, CAE, UAS, Raichur, India \\ ${ }^{2} U A S, G K V K$, Bangalore, India \\ *Corresponding author
}

\section{A B S T R A C T}

\section{Keywords \\ Extrusion, Barnyard millet, Extruder operating parameters, Physical properties \\ Article Info \\ Accepted: 07 September 2020 Available Online: 10 October 2020}

A study was undertaken to develop an extruded product using three composite formulation of barnyard millet (BM) and maize (M) grits (180 micron). The formulations (BM: $\mathrm{M}-70: 30,60: 40$ and 50:50) were extruded using a twin screw extruder. Among the three formulations, the 50:50 was reported to be best based on the sensory evaluation. The temperature range of $100-120^{\circ} \mathrm{C}$ for barrel and 350-400 rpm for screw speed were considered. Based on expansion ratio at lower screw speeds of $400 \mathrm{rpm}$, the expansion ratio of products was higher especially for barrel temperature of $110^{\circ} \mathrm{C}$. However, good expanded products (Expansion ratio - 3.949) could be obtained also at optimum screw speed and barrel temperature.

\section{Introduction}

Barnyard millet is the fastest growing millet and its originated in eastern India. As every kind of millet, barnyard millet is also an appropriate food for patients intolerant to gluten which causes celiac disease. Seeds of this crop are nutritious. It can produce ripe grain in 45 days from the sowing time under the optimal weather conditions. Small seeds of barnyard millet are processed on groats that are used for preparation of different types of porridges. These days various Ready-to-eat processed cereal grain formulations are made which are suitable for human consumption without further cooking. These are made primarily from maize, wheat, oats or rice, usually with added flavor and fortifying ingredients (Fast, 1993). Puffed cereals are commonly used as ready-to eat breakfast foods or as ingredients in snack formulations.

Extrusion cooking of millets appears to be highly promising in the preparation of value added traditional and novel food products with good keeping quality. It is an emerging food processing technology in India. A variety of ready-to-eat traditional snacks, breakfast cereals and supplementary foods could be prepared by extrusion cooking technology. However, hardly any commercial product based on small millets is found on the 
shelf. Extruded products are crispy and crunchy in texture similar to the deep oil fried products but, contain only 2-3 \% fat. Extrusion technology can be successfully used for the preparation of many value added products.

\section{Materials and Methods}

The barnyard millet was processed (dehusked) using a Domestic Burr Mill (make: Ashirwad Co., Ahmedabad) subsequently polished in a friction type Rice Polisher (make: Bhavani Industries, Srirangapatna, Karnataka) to get millet rice grains. A domestic grain pulverizer (Plate 1) was used to mill different millet rice grains into suitable flours/grits, which was later sieved using BS-18 mesh 180micron) screen.

\section{Formulation and preparation of samples}

After several trials blending barnyard millet grits with maize grits (BS 18 mesh size) in different formulations (Table 1) were followed to get the best blending effect trials were conducted at optimized extruder operated conditions (Screw speed $-350 \mathrm{rpm}$; Heater no. $1-110^{\circ} \mathrm{C}$, Heater no. $2-50^{\circ} \mathrm{C}$ ). based on trial and error method. The barnyard millet and Maize grits were thoroughly blended and $90 \mathrm{ml}$ of water per $\mathrm{kg}$ of blend was added to bring its moisture content to about $18-20 \%$. The material was equilibrated for about 30 minutes before extrusion

\section{Operating procedure of extruder}

The extruder was primed for actual operation half-an-hour before. After fixing the required 'die', (3 mm circular hole) the main switch was put on. The Heater no. 1 was set at $110^{\circ} \mathrm{C}$ and Heater no. 2 was set at $50^{\circ} \mathrm{C}$ and both were switched on for barrel heating. Cooling water line to solenoid valve is shut till required temperature was reached. The other operational settings namely, screw speed (350 rpm), feeder speed ( $42 \%$ of max) and cutter (36\% of max) were set in the main control panel.

\section{Recipe and procedure for preparation of} barnyard millet extruded type masala

Since the extrudates from the twin screw extruder were bland in taste, they were applied with sweet - sour-spicy mix before serving to sensory panel by following the procedure: Fry extrudates in 3 tsp of sunflower oil (per $100 \mathrm{~g}$ ) and add 2 tsp of spicy mix as a flavoring agent (Chata masala supplied by M/s Sonram Company, Doddbalapur, Bangalore

\section{Sensory Evaluation of Fry extruded type Products}

The prepared products were evaluated for sensory characteristics using nine point hedonic scale method (Ranganna, 1997) by a panel of 10 trained judges along with the commercially available product as a control. Among the three formulations tried, one best extruded product based on good colour, texture, flavour, taste, crispness and overall acceptability, which was used for further studies to optimize the operating parameters of the Twin Screw Extruder.

Optimization of twin screw extruder operating parameters for barnyard millet based ready-to-eat products

The operating parameters of the twin screw extruder mainly, the barrel temperature and the screw speed, were optimized for the various 'best selected' barnyard millet maize based extruded products. Three barrel temperatures and three screw speeds were selected in factorial combinations to produce extrudates from the already finalized barnyard millet: Maize Grit combinations. The extrudates were analyzed for physical parameters like expansion ratio, water 
absorption index, water solubility index, true density, bulk density, etc. Based on the extrudate characteristics (mainly high expansion ratio), the optimum screw speed and barrel temperature were selected.

\section{Expansion ratio}

The ratio of diameter of extrudate to the diameter of 'die' was used to express the degree of expansion of extrudates (Fan et al., 1996). The diameter of extrudate was determined as the mean of 10 random measurements made with a vernier caliper. The extrudates expansion ratio was then calculated as Table 2:

Expansion ratio $(m / m)=\frac{\text { Extrudate Diameter }(m)}{\text { Die Diameter }(m)}$

\section{Water Absorption Index (WAI) and Water Solubility Index (WSI)}

WAI and WSI were determined by the method described by Anderson (1982). The extruded puffs were milled to a mean particle size of $200-250 \mu \mathrm{m}$. About $2.5 \mathrm{~g}$ of sample was dispersed in $25 \mathrm{ml}$ distilled water and a glass rod was used to break up any lumps. The sample was stirred for $30 \mathrm{~min}$. The dispersion were rinsed into a tarred centrifuged tube, made up to $32.5 \mathrm{~g}$ and centrifuged at $4000 \mathrm{rpm}-\mathrm{g}$ for $15 \mathrm{~min}$. The supernatant was decanted for determination of its solid content and sediment was weighed. WAI and WSI were calculated as:

Water Absorption Index (WAI $)=\frac{\text { Weight of wet sediment }(\mathrm{g})}{\text { Intial Weight of dry solids taken }(\mathrm{g})} \ldots .2$

Water Solubility Index (WI) $=\frac{\text { Weight of dissolved solids in supernatant (g) }}{\text { Weight of dry solids (g) }} \times 10 \mathrm{mmmm}$ (3)

True density
True density of extruded barnyard millet maize based extruded products was determined as per the method suggested by Deshpande and Poshadri (2011). A known weight (1 g) of extrudate was powdered and the ground sample was poured into a burette containing toluene. The rise in volume in the burette was noted as the true volume of the sample. Then the true density was calculated as:

True density $\left(\mathrm{kg} / \mathrm{m}^{3}\right)=\frac{\text { Weight of ground sample of extrudate }(\mathrm{kg})}{\text { Rise of toulene level }\left(\mathrm{m}^{3}\right)} \ldots 4$

\section{Individual extrudate density}

The average sample diameter (d) and length (L) of 25 extrudates were determined using a vernier caliper (least count $0.02 \mathrm{~mm}$ ) assuming the extrudates as cylinder (Launay and Lisch., 1983). The volume of each sample was computed as $\left(\pi \mathrm{d}^{2} \mathrm{~L} / 4\right)$. By measuring the mass of each extrudate, the value of bulk density of individual extrudate was computed as below. The mean of 25 readings was recorded as bulk density.

Bulk density $\left(\mathrm{kg} / \mathrm{m}^{3}\right)=\frac{\text { Mass of extrudates }(\mathrm{kg})}{\text { Volume of extrudates }\left(\mathrm{m}^{3}\right)} . .5$

\section{Results and Discussion}

Sensory characteristics of barnyard millet based extruded products products

\section{Colour}

The mean sensory scores for colour of barnyard millet based extrudates ranged from 7.42 to 7.74 and the control product scored 8.46. There was no significant difference between extrudates from mixes and control. The highest colour score was recorded for control followed by $\mathrm{Bc}_{1}$ and $\mathrm{Bc}_{2}$ (Table 3 ).

\section{Texture}

The mean texture scores of barnyard millet 
based extrudates ranged from 7.24 to 8.04 and there was no significant different between the products from formulated mixes and control. The highest score was however recorded by the control (8.40) and the lowest score was for the product of $\mathrm{Bc}_{3}$ formulation. The products of $\mathrm{Bc}_{1}, \mathrm{Bc}_{2}$ and $\mathrm{Bc}_{3}$ were on par with the control as far as the texture was concerned (Table 3).

\section{Flavour}

The sensory score for flavour of barnyard millet based extrudates varied from 7.16 to 7.72 and were on par with the flavor score for the control sample. The highest score was obtained by commercial product (8.54) followed by $\mathrm{Bc}_{1}$.

\section{Taste}

The mean sensory taste scores ranged from 6.96 to 8.02 and the highest score was recorded with control followed by products of $\mathrm{Bc}_{1}$ and $\mathrm{Bc}_{2}$ formulations (Table 3 ).

There was a significant difference between the barnyard millet based extrudates and the control. However, the product of $\mathrm{Bc}_{1}$ was on par with the control.

\section{Crispness}

With regard to crispness, there was a significant difference between the barnyard millet based products and control. The mean sensory scores of developed products ranged from 6.88 to 7.78. The highest score was recorded with control (8.28) and it is on par with treatments $\mathrm{Bc}_{1}$ and $\mathrm{Bc}_{2}$ (Table 3 ).

\section{Overall acceptability}

The mean sensory scores of barnyard millet extrudates ranged from 6.92 to 7.96 (Table 3). The highest score for overall acceptability (8.41) was recorded for the control sample.
With an acceptability score of 7.96, the product of formulation $\mathrm{Bc}_{1}$ was reckoned to be on par with commercial control product.

\section{Selection of best product through sensory evaluation}

Sensory evaluation of barnyard millets based ready-to-eat expanded products has showed that (Plate 2), barnyard millet, maize grits combinations (Table 3) was to be the best due to its bitter taste in barnyard millet, for further studies and factorial experimental combinations of three screw speeds $(350,400$ $\& 450 \mathrm{rpm})$ and barrel temperatures $(100,110$ and $120{ }^{\circ} \mathrm{C}$ ) were selected and the resultant products were analyzed for the physical parameters namely, expansion ratio, water solubility index, water absorption index, true density and bulk density.

\section{Expansion ratio}

The effect of twin screw extruder operating parameters namely, barrel temperature and screw speed on the expansion ratio of barnyard millet - maize based extruded products was observed (Fig. 1). It was observed that at screw speed of $400 \mathrm{rpm}\left(\mathrm{s}_{2}\right)$, the expansion ratio of products was higher especially for barrel temperature of $100^{\circ} \mathrm{C}$ $\left(t_{1}\right)$. However, good expanded products (Expansion ratio- 3.675) could be obtained with higher screw speed of $450 \mathrm{rpm}\left(\mathrm{s}_{3}\right)$ at $120^{\circ} \mathrm{C}\left(\mathrm{t}_{3}\right)$ barrel temperature.

Based on the experimental trials, it was clear that the maximum expansion ratio of 3.949 could be achieved when the barrel temperature was $100^{\circ} \mathrm{C}\left(\mathrm{t}_{1}\right)$ and screw speed of $450 \mathrm{rpm}\left(\mathrm{s}_{3}\right)$, in barnyard millet - maize based formulations. Similar results were reported by Bhattacharya, M. and Hanna, M.A (1987a) for extruded products. 
Table.1 Different formulations of barnyard millet based extruded product

\begin{tabular}{|l|l|l|l|}
\hline $\begin{array}{l}\text { Barnyard millet } \\
\text { \& Code }\end{array}$ & $\begin{array}{l}\text { Barnyard } \\
\text { millet Grits }(\%)\end{array}$ & $\begin{array}{l}\text { Maize Grits } \\
(\mathbf{\%})\end{array}$ & $\begin{array}{l}\text { Moisture } \\
\text { Content of Blend }(\% \mathbf{w b})\end{array}$ \\
\hline $\mathrm{Bc}_{1}$ & 50 & 50 & 18 \\
\hline $\mathrm{Bc}_{2}$ & 60 & 40 & 18 \\
\hline $\mathrm{Bc}_{3}$ & 70 & 30 & 18 \\
\hline
\end{tabular}

Table.2 Optimization of twin screw extruder operating parameters for barnyard millet based ready-to-eat products

\begin{tabular}{|l|l|l|}
\hline Selected Formulation & \multicolumn{2}{|l|}{ Independent Variable } \\
\hline \multirow{3}{*}{$\begin{array}{l}\text { Barnyard millet } \mathbf{( 5 0 \% )} \\
\text { maize } \mathbf{( 5 0 \% )}\end{array}$} & $\begin{array}{l}\text { Temperature }\left({ }^{\mathbf{0}} \mathbf{C}\right) \\
\text { Sem }\end{array}$ & Screw Speed (rpm) \\
\hline & 110 & 350 \\
\hline 120 & 400 \\
\hline
\end{tabular}

Table.3 Mean sensory scores of barnyard millet based ready-to-eat hot extruded products

\begin{tabular}{|c|c|c|c|c|c|c|c|}
\hline $\begin{array}{l}\text { Millet } \\
\text { Formulation }\end{array}$ & \multicolumn{2}{|c|}{ Colour } & Texture & Flavour & Taste & Crispness & $\begin{array}{l}\text { Overall } \\
\text { acceptability }\end{array}$ \\
\hline $\mathrm{Bc}_{1}$ & \multicolumn{2}{|l|}{7.74} & 8.04 & 7.72 & 8.02 & 7.78 & 7.96 \\
\hline $\mathrm{Bc}_{2}$ & \multicolumn{2}{|l|}{7.44} & 7.66 & 7.44 & 7.36 & 7.50 & 7.34 \\
\hline $\mathrm{Bc}_{3}$ & \multicolumn{2}{|l|}{7.42} & 7.24 & 7.16 & 6.96 & 6.88 & 6.92 \\
\hline Control & \multicolumn{2}{|l|}{8.46} & 8.40 & 8.54 & 8.54 & 8.28 & 8.41 \\
\hline GM & \multicolumn{2}{|l|}{7.76} & 7.83 & 7.68 & 7.68 & 7.99 & 7.66 \\
\hline F-test & \multicolumn{2}{|l|}{ NS } & NS & NS & $*$ & $*$ & $* *$ \\
\hline CD@5\% & - & - & - & 0.97 & 0.78 & 0.86 & \\
\hline SEm \pm & 0.28 & 0.28 & 0.32 & 0.32 & 0.26 & 0.28 & \\
\hline
\end{tabular}

$\mathrm{Bc}_{1}$ - Barnyard millet rice grits (50\%): Corn grits (50\%);

$\mathrm{Bc}_{2}$ - Barnyard millet rice grits (60\%): Corn grits (40\%);

$\mathrm{Bc}_{3}$ - Barnyard millet rice grits (70\%): Corn grits (30\%);

NS - Non significant; * - Significant at $5 \%$; ** - Highly Significan

Plate.1 Primary processing machineries

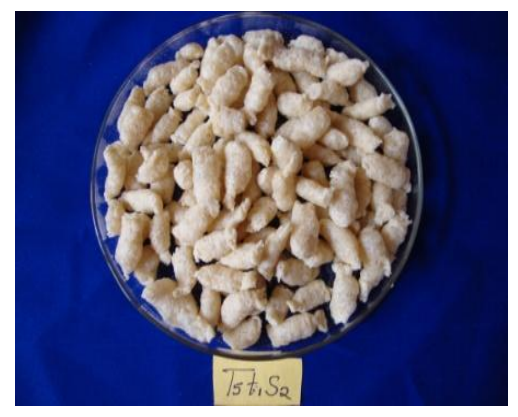


Plate.2 Sensory Evaluation of Ready-to-eat expand extruded Products

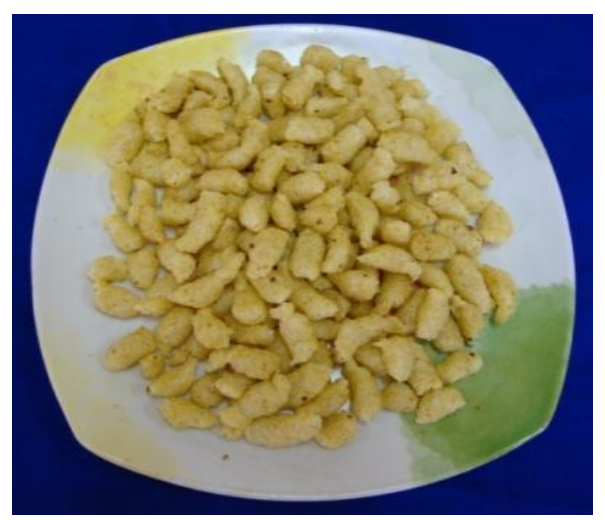

Fig.1 Effect of twin screw extruder operating parameters on Expansion Ratio of barnyard millet based ready-to-eat extruded products

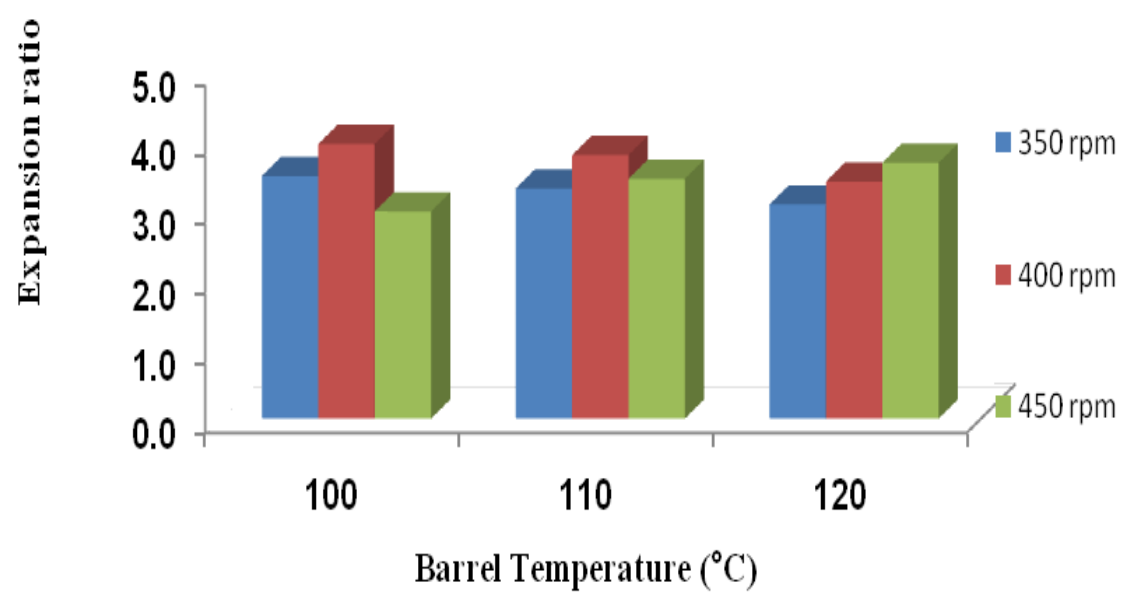

Fig.2 Effect of twin screw extruder operating parameters on WAI of barnyard millet based ready-to-eat extruded products

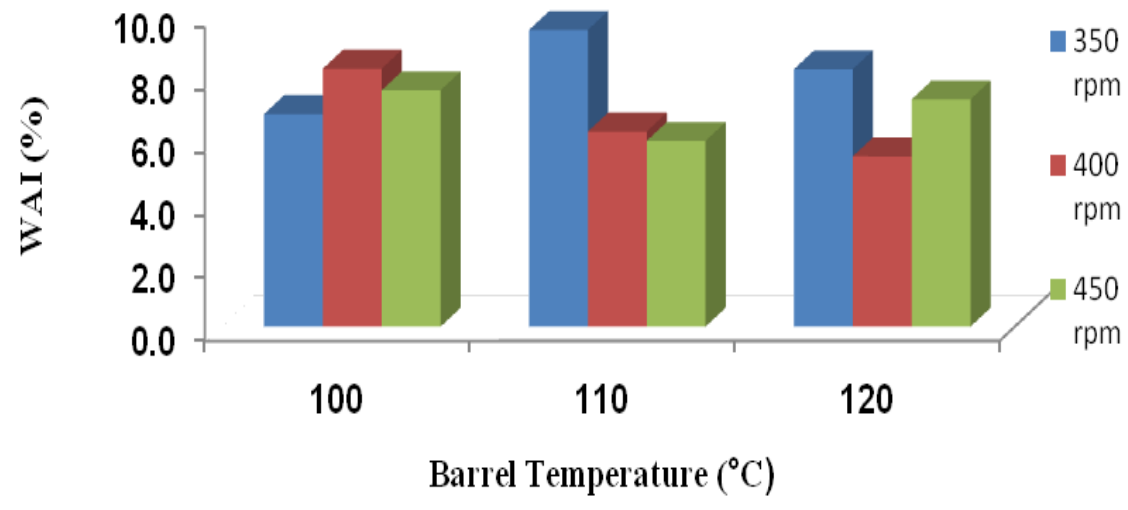


Fig.3 Effect of twin screw extruder operating parameters on WSI of barnyard millet based readyto-eat extruded products

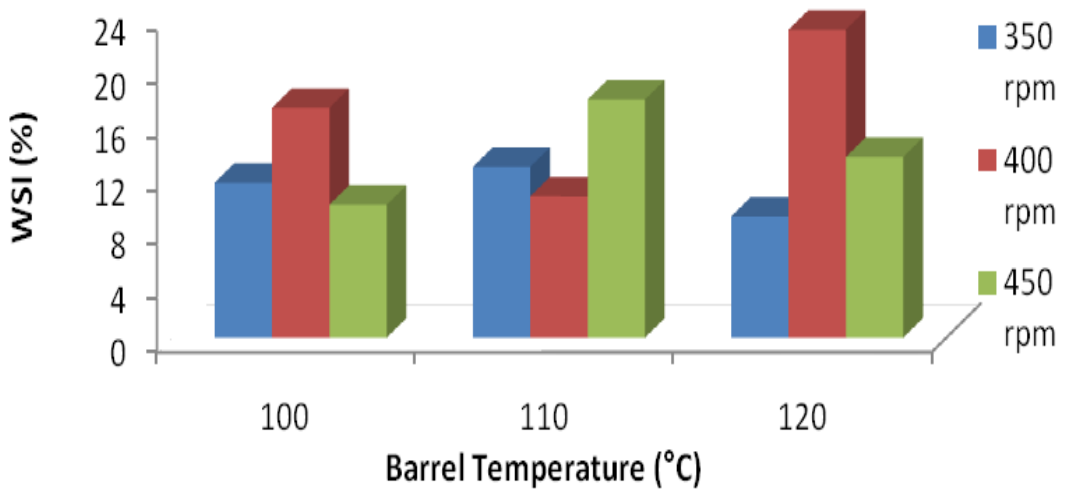

Fig.4 Effect of twin screw extruder operating parameters on True density of barnyard millet based ready-to-eat extruded products

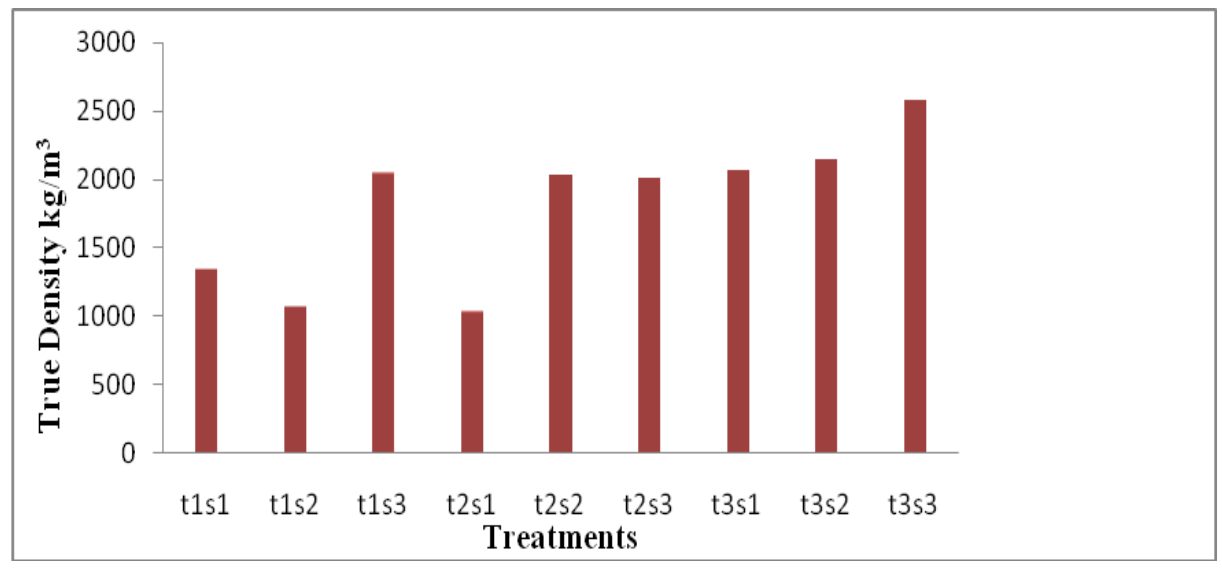

Fig.5 Effect of twin screw extruder operating parameters on Bulk density of barnyard millet based ready-to-eat extruded products

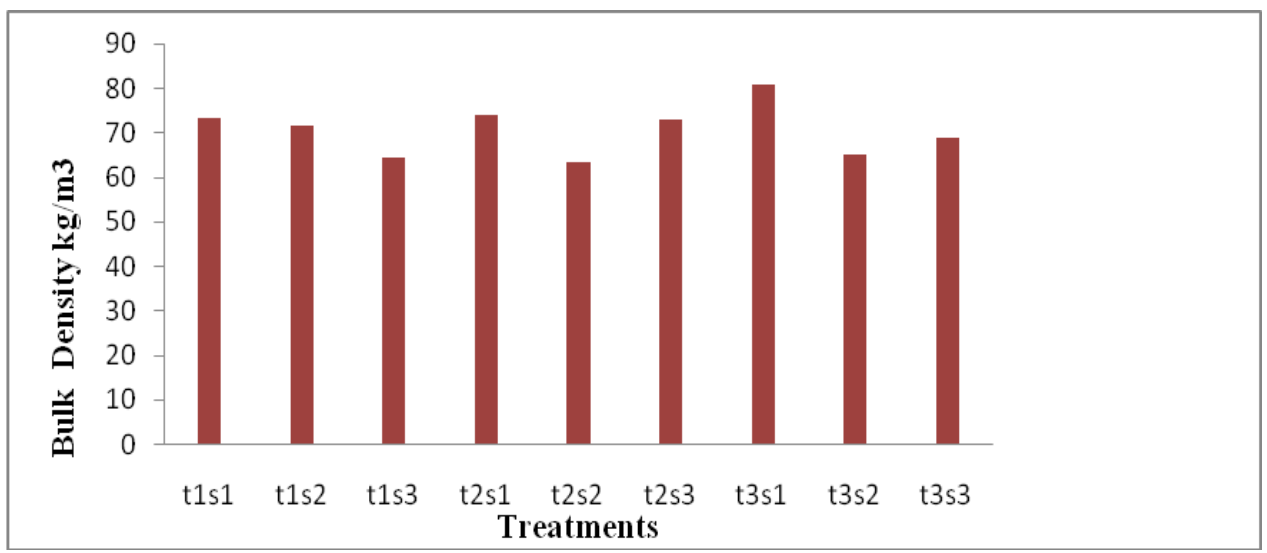




\section{Water absorption index}

The Water Absorption Index of barnyard millet based products (Fig. 2) ranged from 5.420 to 9.445 . The highest value of WAI was recorded in $\mathrm{t}_{2} \mathrm{~s}_{1}$ combination and the lowest was recorded in $t_{3} s_{2}$. Similar results were recorded by Williams (1977). The research was oriented towards the development of low water absorption index product which was succeeded in the present study that helps in maintenance of more air pockets in the product which is desirable extruded materials.

\section{Water Solubility Index (WSI)}

The Water Absorption Index of barnyard millet based products (Fig. 3) ranged 9.0565 to 23.0260. The highest value of WSI was recorded in $\mathrm{t}_{3} \mathrm{~S}_{2}$ combination and the lowest value was recorded in $\mathrm{t} 3 \mathrm{~s} 1$. WSI data indicated that both the barrel temperature and screw speed showed highly significant effect on WSI of barnyard millet based products.

In the present study, the extrudates from small millets showed high WSI which was due to high degree of gelatinization achieved during extrusion cooking. However, the variation in WSI was understandable since the processing temperature (barrel) and the screw speed varied for different products. These findings are supported by the findings of Anderson et al., (1969), Badrie and Mellows (1991) and Tang and Ding (1994).

\section{True density and Bulk density}

The effect of twin screw extruder screw speed on the true and bulk density of barnyard millets based products (Fig. 4 and 5) indicated that, for different screw speed and temperature, true density of products varied considerably from $1029-2580 \mathrm{~kg} / \mathrm{m}^{3}$. Similarly, the bulk density of extruded type products for different screw speed varied from $64.30-80.87 \mathrm{~kg} / \mathrm{m}^{3}$ for barnyard millet. Similar results were found by Thymi et al., (2005) and Harmann and Harper (1973).

In conclusion the study clearly revealed that preparation of extruded products using combination 50:50 $\left(\mathrm{Bc}_{1}\right)$ of barnyard millet and maize grits under a good hygienic environment improved the product acceptability as compared to commercially available samples (control). The best quality as per the lower water absorption index value and highest expansion ratio, water solubility index, bulk density and true density was observed in the product developed under the extruder barrel temperature and screw speed of $120^{\circ} \mathrm{C}$ and 400 and $450 \mathrm{rpm}$.

\section{References}

Anderson R A; Conway H F; Pfeifer V F; Griffin E L. 1996. Gelatinization of grits by roll and extrusion cooking. Cereal Sci. Today, 14: 4-12.

Anderson R A. 1982. Water absorption and solubility and amylograph characteristics of roll-Cooked small grain products. Cereal Chemistry, 59: 265- 269.

Bhattacharya M; Hanna M A. 1987. Kinetics of starch gelatinization during extrusion cooking. J. Food Sci., 52(3): 764-766. .

Badrie N; Mellowes. 1991. Texture and micro structure of cassava (Manihotes culenta Crantz.) flour extrudate. J. Food Sci., 56(5): 1319-1323.

Deshpande H; Poshadri A. 2011. Physical and sensory characteristics of extruded snacks prepared from foxtail millet based composite flours. Int. Research Food. J., 18:730-735.

Fan J; Mitchell J R; Blanchard J M V. 1996. The effect of sugars on the extrusion of maize grits: The role of the glass transition in determining product 
density and shape. Int. J. Food Sci. Tech., 31:55-65.

Fast R B.1993. Manufacturing Technology of Ready-to-Eat Cereals. St. Paul editions, Minnesota, USA, pp.15-42.

Harmann D V; Harper J M. 1973. Effect of extruder geometry on torque and flow. Trans. of the ASAE. 16(18): 11751178.

Launay B; Lisch L M. 1983. Twin screw extrusion cooking of starches: flow behaviour of starch pastes, expansion and mechanical properties of extrudates. J. Food. Engg., 2:259-280 (1983).

Ranganna S. 1997. Manual of analysis and quality control for fruit and vegetable products. Tata McGraw-Hill Publishing Company Limited, New Delhi.

Tang L; Ding Y. 1994. Relationship between functional properties and macro molecular modifications of extruded corn starch. Cereal Chem., 71(2): 364369.

Thymi S; Krokida M K; Pappa A; Maroulis Z B. 2005. Structural properties of extruded corn starch. J. Food Engg., 68: 519-526.

Williams M A. 1997. Direct extrusion of convenience foods. Cereal Foods World, 22(4): 152-154

\section{How to cite this article:}

Sudha Devi, G. and Palanimuthu, V. 2020. Study and Development of Barnyard Millet Based Ready to Eat Product. Int.J.Curr.Microbiol.App.Sci. 9(10): 738-746.

doi: https://doi.org/10.20546/ijcmas.2020.910.089 